\title{
Cognitive Styles and Knowledge of Operational Procedures of Electric Appliances
}

\author{
Mamoru Okada ${ }^{1, *}$, Akio Ishimoto ${ }^{2}$, and Toshiki Yamaoka ${ }^{3}$ \\ ${ }^{1}$ Wakayama University Graduate School of System Engineering Wakayama University, \\ 930 Sakaedani, Wakayama City, Wakayama, Japan (*Until March 2006) \\ mamoru-okada@hi-ho.ne.jp \\ ${ }^{2}$ Research Institute of Human Engineering for Quality Life, Kowa Awashin Bldg. 3rd Floor, \\ 3-7, Awaji-machi 3-chome, Chuo-ku, Osaka-shi, Osaka, Japan \\ ishimoto@hql.jp \\ ${ }^{3}$ Department of Design and Information Sciences, Faculty of Systems Engineering, \\ Wakayama University, 930 Sakaedani, Wakayama City, Wakayama, Japan \\ yamaoka@sys.wakayama-u.ac.jp
}

\begin{abstract}
The objective of this research is to investigate the relationship between user's knowledge of operation procedures for some electric appliances and their cognitive styles. First, questionnaires were given to the participants. The participants answered below questions about cognitive styles. Second, to investigate the participants' knowledge of operating procedures of the electric appliances, participants were asked to write free text description on how to use an appliance without actually operating it. We found certain kinds of knowledge about operation procedures were linked to user's cognitive style.
\end{abstract}

Keywords: cognitive style, mental model, operating procedure, electronic appliance.

\section{Introduction}

The objective of this research is to investigate the relationship between user's knowledge of operation procedures for some electric appliances and their cognitive styles. The electric appliances investigated were home electric appliances, IT devices, information kiosks, etc., that are used in everyday life.

The first author conducted this study in Wakayama University Graduate School of System Engineering.

\section{Methods}

\subsection{Questionnaires and Experiment}

22 of the participants were in their 20 s and 30s, 11 were in their 50s, and 22 were in their 65 or older. The studied appliances consisted of automatic teller machines (ATMs), air 
conditioners, copy machines, CD/radio cassette recorders, computerized dictionaries, FAX machines, home video games and electric massagers for household use.

First, questionnaires were given to the participants. The participants answered below questions about cognitive styles.

Q Please select one of A or B.

Q1.

A. I am cautious in my thinking.

B. I am not cautious in my thinking.

Q2.

A. I count my own opinions.

B. I count the many's opinions. Q3.
A. I am meticulous.
B. I am not meticulous.

Q4.

A. I prefer to play it by ear.

B. I prefer to make a clear decision.

Second, to investigate the participants' knowledge of operating procedures for the electric appliances, an experiment was conducted. The experimental method consisted of the following procedures:

1. An experimenter explained the electric appliance and the goal of job, and showed a picture of it. (Table 1.).

2. The participant wrote out a free description on one card for a step to perform the task, without actually using the device.

The experiment was conducted for each participant and for each appliance.

Table 1. Samples of experimental tasks

\begin{tabular}{|c|c|c|c|c|c|}
\hline Appliance & erse Captio & Job & Start & End & Illustration \\
\hline Air conditioner & \begin{tabular}{|l|} 
The \\
machine is \\
for \\
controlling \\
temperature
\end{tabular} & $\begin{array}{l}\text { There is an air } \\
\text { conditioner. Now } \\
\text { you are before } \\
\text { going to bed. Set } \\
\text { the air } \\
\text { conditioner to } \\
\text { tum on the } \\
\text { heater } \\
\text { automatically }\end{array}$ & $\begin{array}{l}\text { Plug the } \\
\text { power } \\
\text { ords for } \\
\text { the air } \\
\text { conditioner } \\
\text { into } \\
\text { electrical } \\
\text { wall } \\
\text { outlets. } \\
\end{array}$ & $\begin{array}{l}\text { Power on the } \\
\text { air } \\
\text { onditioner } \\
\text { automatically. } \\
\\
\end{array}$ & \\
\hline Fax machine & $\begin{array}{l}\text { The } \\
\text { machine is } \\
\text { to transfer } \\
\text { copies of } \\
\text { documents. }\end{array}$ & $\begin{array}{l}\text { There are an fax } \\
\text { machine and a } \\
\text { document. } \\
\text { Transfer copies } \\
\text { to one of your } \\
\text { friends from } \\
\text { your fax } \\
\text { machine. }\end{array}$ & $\begin{array}{l}\text { Plug the } \\
\text { power } \\
\text { cords for } \\
\text { the fax } \\
\text { machine } \\
\text { into } \\
\text { electrical } \\
\text { wall } \\
\text { outlets. }\end{array}$ & $\begin{array}{l}\text { Have sent the } \\
\text { copy to your } \\
\text { friend. }\end{array}$ & \\
\hline
\end{tabular}




\subsection{Analysis}

These cards were classified into about 300 tasks.

The participants were classified according to what tasks they answered using Hayashi's Quantification Theory III and Cluster Analysis. This analysis was conducted with respect to each appliance. The number of the clusters is from five to seven per appliance. The clusters are described as "Knowledge of Operational Procedure Type" in this paper.

We evaluated correlate between the clusters and the answers about cognitive styles (Q1-Q4) by applying Fisher's Exact Test (Extended).

\section{Results and Discussion}

Table 2 shows the results of the evaluation on Knowledge of Operational Procedure Type -Cognitive Style correlation. Air Conditioners correlate with Q2 (I count my own opinions / I count the many's opinions). FAX Machine correlate with Q3 (I am meticulous / I am not meticulous).

Table 2. Knowledge of Operational Procedure Type -Cognitive Style Correlation

\begin{tabular}{|l||l|l|l|l|}
\hline \multicolumn{1}{|c|}{ Question } & Q1 & Q2 & Q3 \\
Appliance & Cautious & Independence & Q4 \\
Meticulous & Play it by ear \\
\hline \hline ATM & & & & \\
\hline Air Conditioner & & & & \\
\hline Copy Machine & & & & \\
\hline CD/radio cassette recorder & & & & \\
\hline Computerized Dictionary & & & $*$ & \\
\hline FAX Machine & & & & \\
\hline Home Video Game & & & \\
\hline Electric Massager & & & & \\
\hline
\end{tabular}
$(* *: \mathrm{p}<0.01, *: \mathrm{p}<0.05)$

\subsection{Air Conditioners-Q2}

The knowledge of operational procedure types about air conditioners correlates with Q2 (I count my own opinions / I count the many's opinions). We think the reason comes from that. An air conditioner is used by several users and its function reflects to other people in a family. Therefore the user uses it with communication at home. So the knowledge correlates with if the user prefers to count others' opinions.

\subsection{Fax Machine-Q3}

The knowledge of operational procedure types about fax machines correlate with Q3 (I am meticulous / I am not meticulous). We focus on the type B, because the number of the participants that gave "A. I am meticulous" is most on the type. 


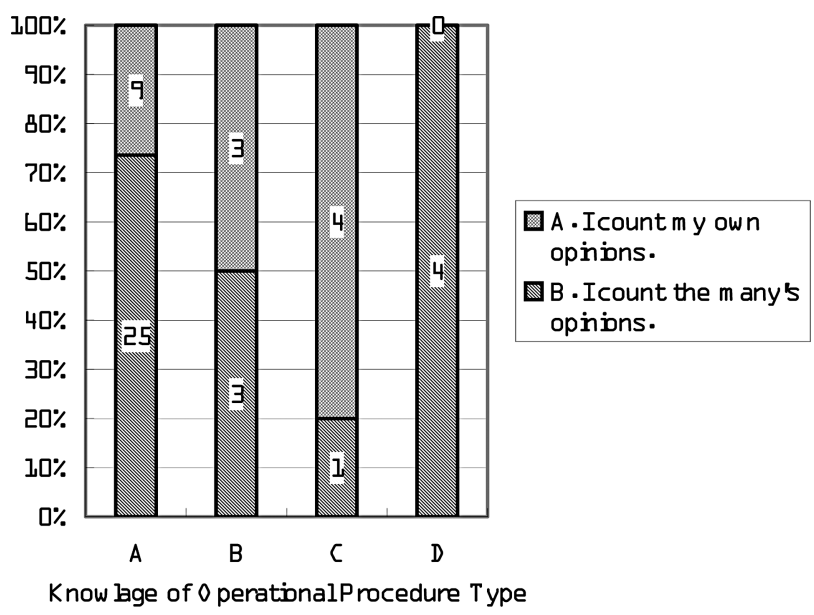

Fig. 1. Rate of Cognitive style (Air Conditioner)

More participants in the type B give "Power on" (63.2\% of the type B) and "Put the machine in the fax mode" ( $73.7 \%$ of the type) as the answer than the other types (0\%-4.8\%). Many participants in the type B think that these procedures should be executed. We think that meticulous users mind upping procedures.

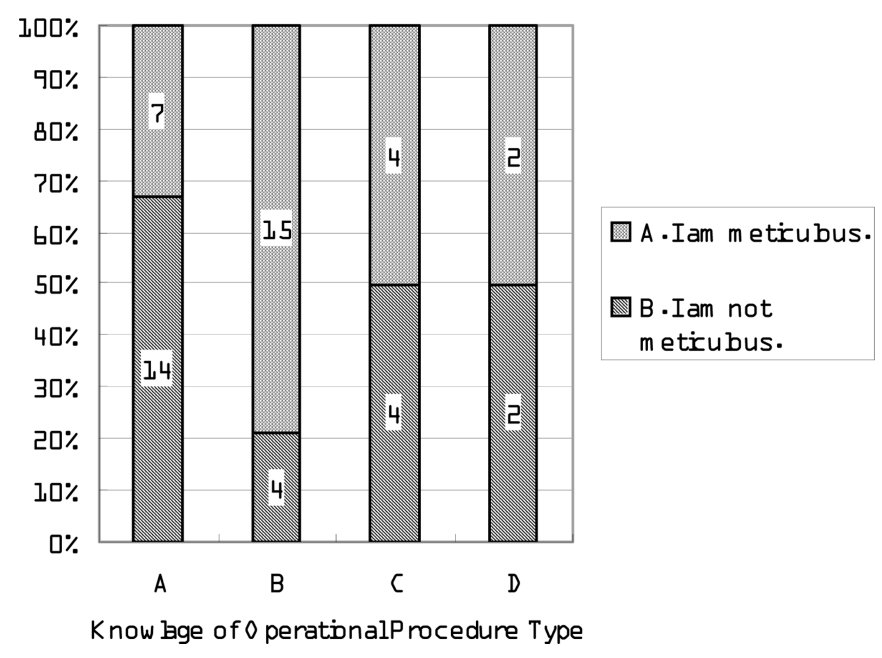

Fig. 2. Rate of Cognitive style (Fax Machine)

\section{Conclusion}

We found certain kinds of knowledge about operation procedures were linked to user's cognitive style. But it is partly and we cannot explain why the others are not 
linked the cognitive styles. We should more study aspect of other cognitive styles, user's experience and their age.

Acknowledgment. Thanks Saori Oku and Masatoshi Rin at Wakayama University for their help.

\section{References}

1. Hidenari, S., Etsuko, T.H., Hiroko, A., Misako, N., Akio, I.: A Massive Usability Test of IT devices for Elderly People Use: A Case Study of Errors using Automatic Teller Machine (ATM) (Supplement). The. Japanese Journal of Ergonomics, Japan Ergonomics Society 38, 224-225 (2002)

2. Hiroko, A., Etsuko, T.H., Misako, N., Hidenari, S., Akio, I.: A Massive Usability Test of IT devices for Elderly People Use: A Case Study of Errors using a Video game Machine (Supplement). The Japanese Journal of Ergonomics, Japan Ergonomics Society 38, 228-229 (2002)

3. Research Institute of Human Engineering for Quality Life. In:The report of the IT barrier free project (2002)

4. Mamoru, O., Takuo, M., Toshiki, Y.: Users' Knowledge of Procedures for Everyday Devices. In: The Ergo-design Technical Group of the Japan Ergonomics Society (2002)

5. Mamoru, O., Takuo, M., Toshiki, Y.: A Study on Users' Assumption of Operating Procedures for Electric Machiner and Apparatus. In: Proceedings of 2002 Meeting of the Kansai Branch, Japan Ergonomics Society, pp. 114-115 (2002) 